University of South Florida

DIGITAL COMMONS

Digital Commons @ University of

@ UNIVERSITY OF SOUTH FLORIDA

South Florida

\title{
Trade Wind fluctuations Associated with El Niño-Southern Oscillation Events
}

Gary T. Mitchum

University of Hawaii, mitchum@usf.edu

Follow this and additional works at: https://digitalcommons.usf.edu/msc_facpub

Part of the Life Sciences Commons

\section{Scholar Commons Citation}

Mitchum, Gary T., "Trade Wind fluctuations Associated with El Niño-Southern Oscillation Events" (1987). Marine Science Faculty Publications. 2077.

https://digitalcommons.usf.edu/msc_facpub/2077

This Article is brought to you for free and open access by the College of Marine Science at Digital Commons @ University of South Florida. It has been accepted for inclusion in Marine Science Faculty Publications by an authorized administrator of Digital Commons @ University of South Florida. For more information, please contact digitalcommons@usf.edu. 


\title{
Trade Wind Fluctuations Associated With El Niño-Southern Oscillation Events
}

\author{
Gary T. Mitchum \\ Tropical Ocean and Global Atmosphere Sea Level Center, Hawaii Institute of Geophysics, University of Hawaii, Honolulu
}

\begin{abstract}
Wind fields associated with El Niño-Southern Oscillation (ENSO) events are investigated using 20 years (1965-1984) of monthly mean wind vectors along a ship track from $30^{\circ} \mathrm{S}$ to $30^{\circ} \mathrm{N}$ in the western Pacific Ocean. The analysis shows that off-equatorial trade wind fluctuations play a significant role in ENSO events. In particular, the meridional component is found to have strong deviations during ENSO events. Southerly deviations from the mean meridional field are noted during the ENSO events of 1965, 1972, 1976, and 1982. The trade wind deviations are consistent with atmospheric convergence into an equatorial convection region to the east of the ship track. It is hypothesized that these wind fields can cause anomalous oceanic mass convergence toward the equator.
\end{abstract}

\section{INTRODUCTION}

A hypothesis for the initiation of El Niño-Southern Oscillation (ENSO) events was originated by Wyrtki [1975]. The hypothesis states that relaxation of the normal easterlies in the central and western tropical Pacific removes the force which balances the east-west slope of the sea level surface and thermocline. As a consequence, the slope relaxes by the release of mass as a Kelvin surge. Support for this hypothesis was provided within a few years by various modeling efforts [e.g., Hurlburt et al., 1976; McCreary, 1976; Busalacchi and O'Brien, 1981] and by analysis of the sea level field during the 1972 event [Wyrtki, 1977].

One result of the success of this hypothesis has been a concentration of attention on deviations in the zonal wind component near the equator in the western Pacific. Relatively little attention, on the other hand, has been given to the meridional wind component or to wind fluctuations off the equator. Recently, though, Luther and Harrison [1984] pointed out in their study of winds measured at tropical Pacific islands that the 1963 ENSO event appeared to be forced by the meridional wind component. They suggested the possibility that the net oceanic mass divergence due to this wind component was responsible. Also, Harrison [1984] pointed out that for the 1982 ENSO event the westerly wind deviations north of the equator were preceded by a longitudinally narrow southerly jet south of the equator. This jet eventually crossed the equator and served as the source of the westerly deviations north of the equator. Chang and Lum [1985] discuss an interesting connection of equatorward winds associated with cold surges from the Asian continent to tropical convective events. Along somewhat similar lines, other researchers [Cane and Zebiak, 1985; Zebiak, 1986] have pointed out the association of westerly deviations at the equator with atmospheric convergence into a convection region. This convergence also involves the meridional wind component.

Concern about the meridional structure of the wind field arose in conjunction with questions about the meridional structure of the sea level field during ENSO events. Mitchum and Wyrtki [1986, also manuscript in preparation,

Copyright 1987 by the American Geophysical Union.

Paper number $7 \mathrm{C} 0447$.

0148-0227/87/007C-0447\$05.00
1987] note strong interhemispheric differences in the western Pacific tropical sea level field during the 1976 and 1982-1983 ENSO events. In order to try to understand this meridional structure, a study of the meridional variation in the time series of the western Pacific wind forcing was undertaken. The next section of this paper describes the data used and discusses the features of the wind forcing as a function of meridional position and time. The subsequent section discusses the observed features of the wind forcing in relationship to the occurrence of ENSO events.

\section{ANAlysis of THE Wind Field}

\subsection{Data Sources and Processing}

A 20-year (1965-1984) time series of monthly mean wind vectors on a $2^{\circ}$ latitude by $10^{\circ}$ longitude grid running from $30^{\circ} \mathrm{S}$ to $30^{\circ} \mathrm{N}$ and centered on a ship track from Australia to Japan (Figure 1) has been assembled. Data from the Comprehensive Ocean Atmosphere Data Set (COADS) [Woodruffet al., 1987] is used for 1965-1979. The data in the COADS file are provided on a $2^{\circ}$ by $2^{\circ}$ grid. At each $2^{\circ}$ of latitude all the observations for a given month in a $10^{\circ}$ longitude range centered on the ship track are averaged. This $10^{\circ}$ longitude range includes five $2^{\circ}$ by $2^{\circ}$ boxes which all lie at the same latitude. Digitized versions of analyzed wind fields [Sadler et al., 1987] were provided by J. Sadler for 1979-1984. These data were provided with a $2.5^{\circ}$ latitude spacing and were interpolated (using a cubic spline) to the same $2^{\circ}$ latitude grid used by COADS. The 1965-1984 series is constructed by combining COADS data from 1965-1978, Sadler's data for 1980-1984, and the average of the two for 1979. The two data sources agree very well for the 1 year of overlap (1979). For example, the two sources have an average squared correlation coefficient of over 0.85 .

It is important to point out that only data on the ship track are used in this study. This is because the density of observations falls off rapidly off the track. For example, during 1979 there is an average of 76 observations per month in the $2^{\circ}$ by $10^{\circ}$ box centered on the track at the equator. In non-overlapping $10^{\circ}$ longitude boxes to the east and west, however, there are only 19 and 23 observations per month, respectively. A study of sampling and aliasing by Luther and Harrison [1984] shows that these latter values will yield suspect monthly means. It is also important to realize that before 1979 the situation is even worse. The choice of a 


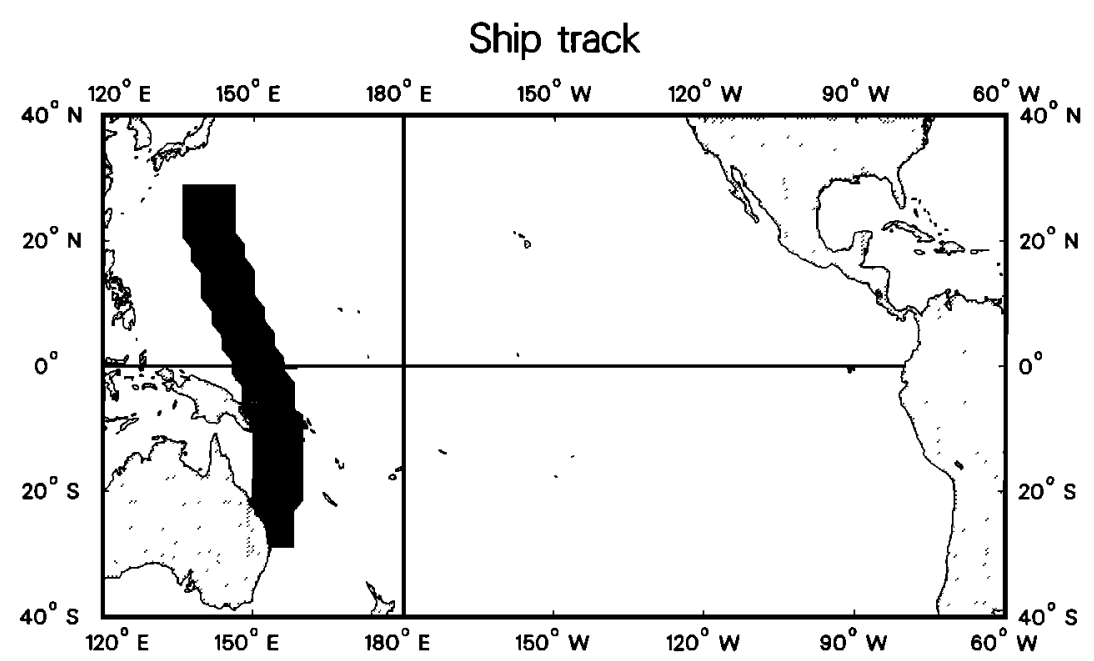

Fig. 1. Location of the area surrounding the ship track from which wind vectors were used in this study.

starting date of 1965 is primarily due to severely decreased numbers of observations in earlier years, even in the ship track.

The resulting monthly mean wind components were used to compute pseudostress deviations. At each grid point and for each month, the wind components were multiplied by the wind speed to create an index of the wind stress components that will be referred to as pseudostress. The coordinate system is right-handed with the zonal coordinate positive eastward. The means of both pseudostress components were computed as a function of latitude (Figure 2). The major features seen in the mean are the northeast trades centered at about $14^{\circ} \mathrm{N}$, the southeast trades centered at about $16^{\circ} \mathrm{S}$, and relatively small stress within $5^{\circ}$ of the equator. The mean functions shown in Figure 2 were subtracted from the pseudostress data, yielding residuals that will be referred to as the pseudostress deviations. Note that in this coordinate system, positive zonal values are westerly deviations, while positive meridional values are southerly deviations. Note also that the annual cycle has not been removed. The choice of the term deviations is to avoid confusion with the common use in climatology of the term anomalies for a residual formed by subtracting the mean and annual cycle. All calculations described below were also done simply using wind components. No significant differences were found. Pseudostress is used primarily because it is considered to be more physically relevant as an oceanic forcing function.

\subsection{Features of the Pseudostress Fields}

The end result of the processing is a monthly time series of meridional profiles of pseudostress deviations for the period $1965-1984$ at $2^{\circ}$ intervals centered at $29^{\circ} \mathrm{N}, 27^{\circ} \mathrm{N}$, etc. The zonal and meridional components of the pseudostress deviations are contoured in Figure 3. This figure clearly shows that the deviations are strongest off the equator at latitudes of $5^{\circ}$ to $15^{\circ}$ or $20^{\circ}$ and correspond spatially with the trade winds (see Figure 2). The deviations must therefore be considered as representing trade wind fluctuations. The monthly mean data used in this study do not resolve the short-duration westerly bursts near the equator [Luther et al., 1983]. This must be noted because of the evidence that these short-duration events are important in initiating the
Kelvin pulses associated with ENSO events [Lukas et al., 1984].

The zonal $(U)$ field in Figure $3 a$ shows that the westerly deviations have a strong annual cycle with substantial interannual variability. Also, the deviations are clearly more energetic in the northern hemisphere. Specifically, the variance in the northern hemisphere is 1.5 times larger than the variance south of the equator. The zonal deviations tend to be $180^{\circ}$ out of phase across the equator. Note that the strongest westerly deviations north of the equator do not necessarily correspond to the ENSO years of 1965, 1972, 1976, and 1982. Examples of this can be seen by comparing these years with $1966,1967,1974,1980$, or 1981 . This is in accord with the results of Wyrtki and Meyers [1976].

The meridional $(V)$ field is shown in Figure $3 b$. Compared with the zonal component, the meridional deviations are more variable interannually and are more energetic south of

\section{Mean pseudo-stress profiles for $65-84$}

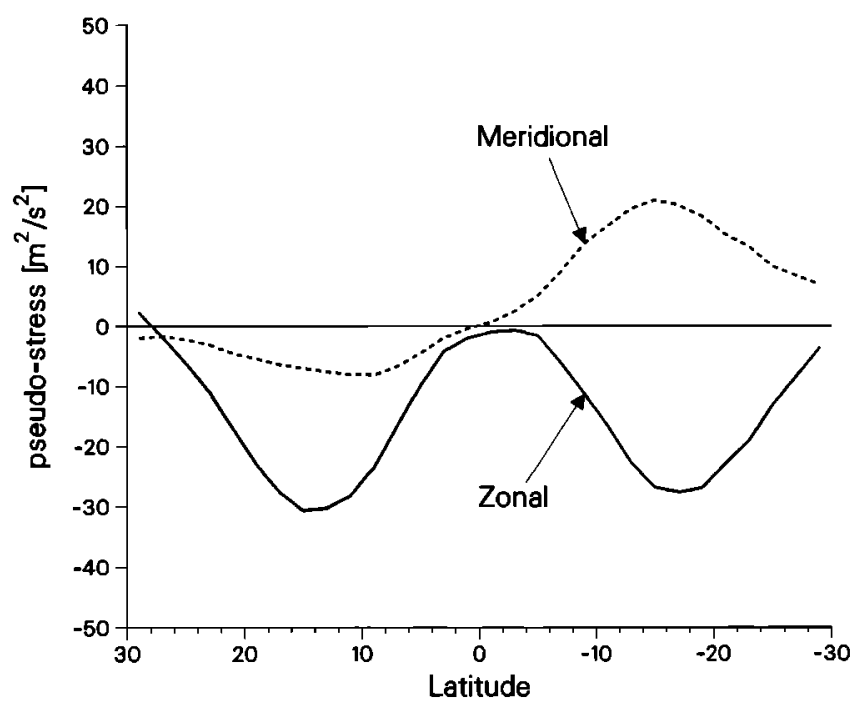

Fig. 2. Means of the pseudostress components for 1965-1984 versus latitude. Units are $\mathrm{m}^{2} / \mathrm{s}^{2}$. The zonal coordinate is positive to the east, and the meridional coordinate is positive to the north. 
a Pseudo-stress U component

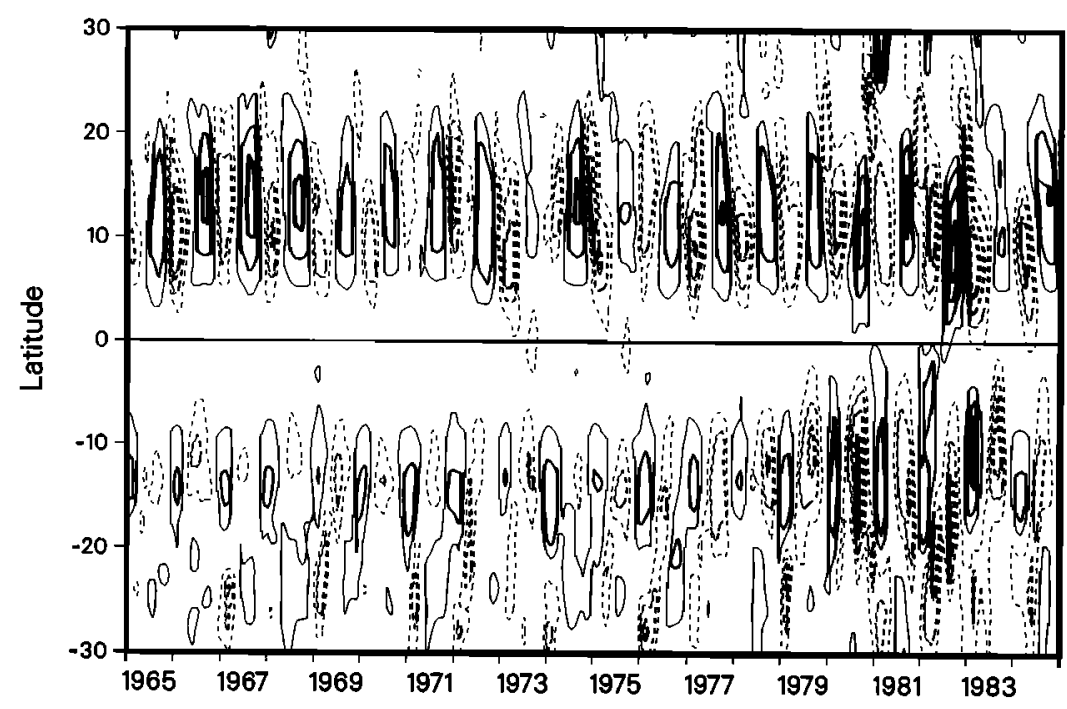

b Pseudo-stress $\quad \mathrm{V}$ component

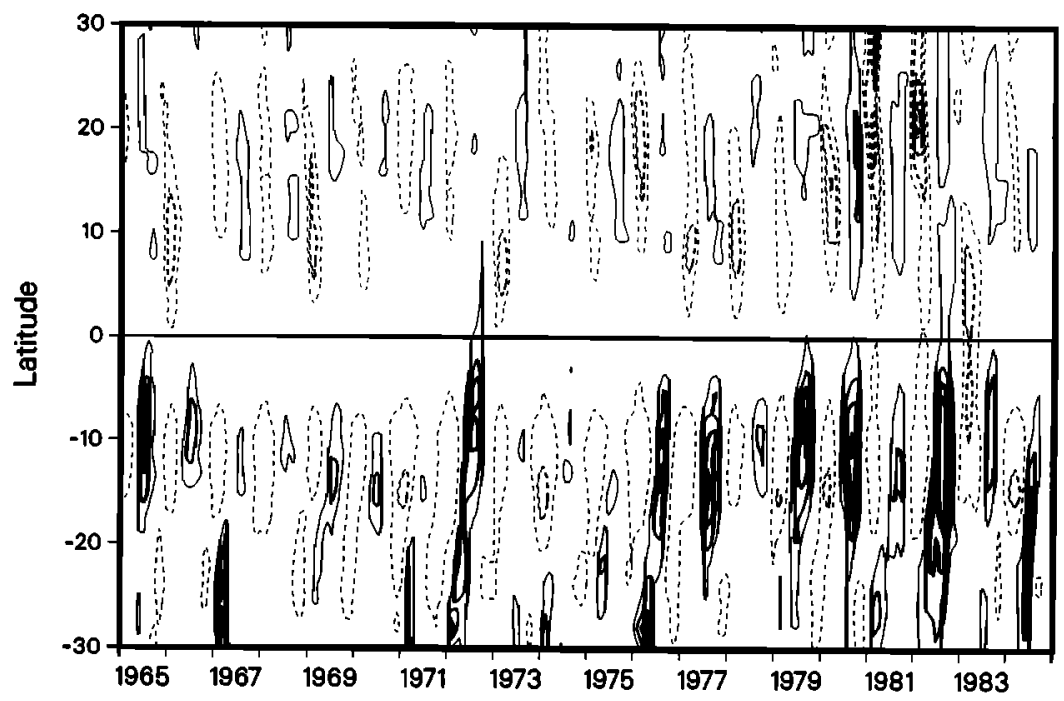

Fig. 3. (a) The zonal ( $U$ ) component of the pseudostress versus latitude and time. Solid (dashed) contours represent positive (negative) deviations from the means. The contour interval is $10 \mathrm{~m}^{2} / \mathrm{s}^{2}$, and the contour lines are thickened in proportion to the value of the contour. For example, the $30-\mathrm{m}^{2} / \mathrm{s}^{2}$ contour is three 1 imes thicker than the $10-\mathrm{m}^{2} / \mathrm{s}^{2}$ one. (b) As in Figure $3 a$ but for the meridional $(V)$ component.

the equator. The variance south of the equator is 1.6 times greater than that north of the equator. Also, these signals are nearly in phase across the equator. Like the zonal component, these deviations are also stronger off the equator. It is interesting to note that the years with strong southerly deviations south of the equator have a closer correspondence to ENSO years than was noted above for the years with strong westerly deviations. The strongest southerly deviations are in the ENSO years and in 1977, 1979, and 1980.

In agreement with Harrison [1984], the ENSO years (1965, 1972,1976 , and 1982) are marked by southerly deviations south of the equator and westerly deviations north of the equator. Thus the variability of the meridional component does seem to be associated with the ENSO events. It is important to note that strong westerly deviations alone do not necessarily correspond to ENSO years (e.g., 1974). Also, there are non-ENSO years (e.g., 1977, 1979, and 1980) with strong southerlies south of the equator.

\section{Discussion}

The features in Figure 3 are studied in relation to the occurrence or non-occurrence of an ENSO event using a very simple index which is formed as follows. The zonal $(U)$ contribution is computed by simply summing the zonal deviations from $15^{\circ} \mathrm{N}$ to $15^{\circ} \mathrm{S}$. The meridional $(V)$ contribution is formed by subtracting the sum of the meridional deviations over $15^{\circ} \mathrm{N}$ to the equator from the sum over $15^{\circ} \mathrm{S}$ to the equator. These quantities index the net westerly and 


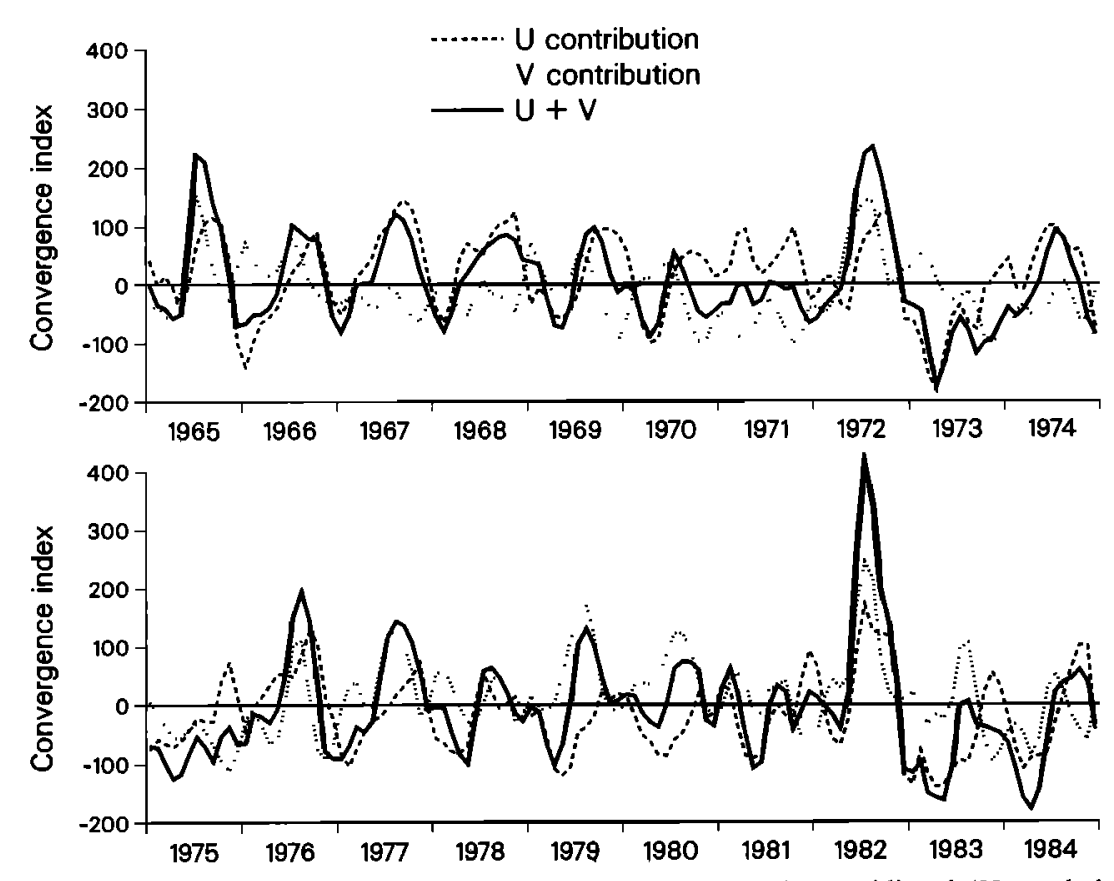

Fig. 4. Time history of the convergence index showing the zonal $(U)$, the meridional $(V)$, and the net $(U+V)$ convergence. Units are arbitrary.

equatorward deviations in the wind field, respectively. These individual contributions and their sum are plotted in Figure 4. The first thing to note in Figure 4 is that the zonal and meridional contributions tend to add constructively only in the ENSO years $1965,1972,1976$, and 1982. These are the only years where the index exceeds 200 . The index also correlates ( $90 \%$ significance level) with the Southern Oscillation index as measured by the atmospheric pressure difference between Easter Island and Darwin (not shown). Furthermore, if it is conceded that 1982 was the largest event and 1965 and 1972 were stronger than 1976, then the size of the index qualitatively agrees with the strength of the ENSO events. Also, in years such as 1967 and 1974, where there are reasonably strong westerly deviations (see Figure $3 a$ ) but no ENSO event, the meridional contribution cancels a significant portion of the contribution due to the zonal component. It is clear that this index works much better at identifying ENSO events than would an index of the net westerly deviation alone (see the dashed line in Figure 4).

But why compute this particular index? The pattern of westerly and equatorward wind deviations is recognized as being consistent with inflow on the western side of a convective region in the tropical atmosphere as described by Zebiak [1986]. These convective regions exist during the mature phase of ENSO in association with patches of anomalously warm sea surface temperature (SST). This forms a physical basis for the association of this particular pattern of zonal and meridional wind deviations with the ENSO events. This is one reason for terming the index in Figure 4 a convergence index.

It is natural to ask what effect these wind deviations will have on the oceanic circulation. It is hypothesized that there is anomalous oceanic mass convergence toward the equator associated with this wind pattern. This hypothesis would explain the large meridional scale of the sea level drop in the western Pacific during ENSO events. This is because it provides a mechanism for supplying off-equatorial mass to the equatorial waveguide from where it is transported eastward in the Kelvin surges. Note also that this off-equatorial mass supply will tend to keep the thermocline from shoaling to the point that the SST will cool and the convective activity will cease. According to this hypothesis, the oceanic response to the wind deviations could serve to sustain the conditions necessary for the convection.

To see how this oceanic mass convergence can be accomplished, first note that westerly wind deviations on either side of the equator will cause Ekman transport toward the equator. Consequently, westerly deviations on both sides of the equator or, more generally, a positive value for the meridional average of the zonal deviations will cause convergence into the equatorial region. Northerly deviations north of the equator and southerly deviations south of the equator will also cause mass convergence due to the proximity of the western boundary. This is because mass taken toward this boundary by the Ekman transport associated with these deviations can then be transported equatorward by coastal-trapped processes. Some evidence that this type of equatorward transport of mass can take place at a western boundary is given by Pazan et al. [1986]. Thus in Figure 4, positive values of the index are interpreted as corresponding to net oceanic mass convergence into the equatorial region, and negative values correspond to net divergence from the equator. This is another reason why the vertical axes in Figure 4 are labeled as a convergence index.

The years 1979 and 1980 are particularly interesting. Consider the zonal (dashed) contribution in Figure 4. Despite strong westerly deviations north of the equator, the easterly deviations south of the equator are strong enough to actually create a divergence from the equatorial region. Consequently, there is not an ENSO event even though the pattern described by Harrison [1984] of southerly deviations south of the equator and westerly deviations north of the 
equator is present. According to the above hypothesis, in these years there are large transports of mass but no net convergence on the equator. Presumably mass is transferred from one hemisphere to the other rather than being released down the equatorial waveguide as a Kelvin surge. It is interesting to note [Donguy and Dessier, 1983] that there were ENSO-like conditions in the western Pacific although there was no basinwide ENSO event.

\section{Summary}

Analysis of the tropical western Pacific wind forcing shows that the ENSO years of 1965, 1972, 1976, and 1982 are clearly associated with westerly and equatorward trade wind deviations. This pattern of wind fluctuations is consistent with atmospheric convergence into a convection region east of the study area. It is hypothesized that oceanic mass convergence toward the equator is associated with these wind deviations. This convergence is due to both zonal and meridional trade wind fluctuations acting in concert. Luther and Harrison [1984] point out that variation in the pattern of wind deviations from one ENSO event to another "is the rule rather than the exception." Recognition of the role of the off-equatorial zonal and meridional trade wind fluctuations helps explain this variability. Future work using more data and models may lead to better indices for prediction and classification of ENSO events.

Acknowledgments. Klaus Wyrtki was closely involved with this work at all stages and provided many invaluable discussions and insights. His participation is gratefully acknowledged. Roger Lukas carefully read an earlier version of this paper and made many comments that greatly improved the final result. J. Sadler and A. Horl provided access to the wind data, and B. Kilonsky provided valuable data management support for this study. The research was supported by the TOGA Sea Level Center through NOAA Cooperative Agreement NA85ABH00032 to the Joint Institute for Marine and Atmospheric Research (JIMAR), University of Hawaii. Hawaii Institute of Geophysics contribution 1881 and JIMAR contribution 87-0133.

\section{REFERENCES}

Busalacchi, A. J., and J. J. O'Brien, Internannual variability of the equatorial Pacific in the 1960s, J. Geophys. Res., 86, $10,901-10,907,1981$.
Cane, M. A., and S. E. Zebiak, A theory for El Niño and the Southern Oscillation, Science, 228, 1085-1086, 1985.

Chang, C.-P., and K. G. Lum, Tropical-midlatitude interactions over Asia and the western Pacific Ocean during the 1983/84 northern winter, Mon. Weather Rev., Il3, 1345-1358, 1985.

Donguy, J.-R., and A. Dessier, El Niño-like events observed in the tropical Pacific, Mon. Weather Rev., 111, 2136-2139, 1983.

Harrison, D. E., The appearance of sustained equatorial surface westerlies during the 1982 Pacific warm event, Science, 224, 1099-1102, 1984.

Hurlburt, H. E., J. C. Kindle, and J. J. O'Brien, A numerical simulation of the onset of El Niño, J. Phys. Oceanogr., 6, $621-631,1976$.

Lukas, R., S. P. Hayes, and K. Wyrtki, Equatorial sea level response during the 1982-1983 El Niño, J. Geophys. Res., 89, $10,425-10,430,1984$.

Luther, D. S., and D. E. Harrison, Observing long-period fluctuations of surface winds in the tropical Pacific: Initial results from island data, Mon. Weather Rev., 112, 285-302, 1984.

Luther, D. S., D. E. Harrison, and R. A. Knox, Zonal winds in the central equatorial Pacific and El Niño, Science, 222, 327-330, 1983.

McCreary, J., Eastern tropical ocean response to changing wind systems: With application to El Niño, J. Phys. Oceanogr., 6, 632-645, 1976.

Mitchum, G. T., and K. Wyrtki, Empirical orthogonal function description of Pacific monthly mean sea level, (abstract), Eos Trans. AGU, 67, 1014, 1986.

Pazan, S. E., W. B. White, M. Inoue, and J. J. O'Brien, Offequatorial influence upon Pacific equatorial dynamic height variability during the 1982-1983 El Niño/Southern Oscillation event, J. Geophys. Res., 91, 8437-8450, 1986.

Sadler, J. C., M. A. Lander, A. M. Hori, and L. K. Oda, Tropical marine climatic atlas, vol. II, Pacific Ocean, UHMET 87-01, Dept. of Meteorol., Univ. of Hawaii, Honolulu, 1987.

Woodruff, S. D., J. Slutz, R. L. Jenne, and P. M. Steurer, A comprehensive ocean-atmosphere data set, Bull. Amer. Meteorol. Soc., in press, 1987.

Wyrtki, K., El Niño-The dynamic response of the equatortal Pacific Ocean to atmospheric forcing, J. Phys. Oceanogr., 5, 572-584, 1975.

Wyrtki, K., Sea level during the 1972 El Niño, J. Phys. Oceanogr., 7, 779-787, 1977.

Wyrtki, K., and G. Meyers, The trade wind field over the Pacific Ocean, J. Appl. Meteorol., 15, 698-704, 1976.

Zebiak, S. E., Atmospheric convergence feedback in a simple model for El Niño, Mon. Weather Rev., I14, 1263-1271, 1986.

G. T. Mitchum, TOGA Sea Level Center, Hawaii Institute of Geophysics, University of Hawaii, Honolulu, HI 96822.

(Received April 9, 1987; accepted April 10, 1987.) 